\title{
Nephritogenicity of glomerular basement membrane: a molecular aspect
}

\author{
Syarifuddin Rauf
}

Department of Child Health, Medical School, Hasanuddin University/ Wahidin Sudirohusodo Hospital, Makassar

\begin{abstract}
Glomerular basement membrane (GBM) has multifunctions. One of its functions is having nephritogenicity which means the ability of an antigen originally from GBM in causing glomerulonephritis, either in experimental animal or in human being. Recent studies on GBM have revealed that its main component is type IV collagen, consists of 6 different isoforms, $\alpha 1$ (IV) to $\alpha 6$ (IV) chains. Genetic studies show that all of the six $\alpha$ chains are encoded by genes located in 2, 13 , and $X$ chromosomes. Nephritogenic antigen in GBM has been identified as $\alpha 3, \alpha 4, \alpha 5$ chains. They are molecules of type IV collagen located in globular domain (NC1 domain) at the carboxyl terminus of the type IV collagen of GBM. They are thought to assemble into a $\alpha 3-\alpha 4-\alpha 5$ (IV) chain helical molecules in human GBM. Other $\alpha$ chains, namely $\alpha 1$ and $\alpha 2$ chain, are not nephritogenic or poorly nephritogenic, while the $\alpha 6$ chain is not located in GBM. The nephritogenicity of GBM has been elucidated as a cause in experimental anti-GMB nephritis, and in Goodpasture and Alport syndromes. [Paediatr Indones $2001 ; 41: 273-278]$
\end{abstract}

Keywords: glomerulonephritis, glomerular basement membrane, nephritogenic antigeng

THE BASEMENT MEMBRANE IS A THIN AND AMORPHOUS specialized extracellular matrix that plays a role in diverse biological events, including embryonic development, maintenance of tissue architecture, protection of tissues and organs from mechanical stress and exogenous factors, tissue remodeling during development and wound healing. ${ }^{1}$ Its function is also to serve as barrier for cell movement and molecule filtration particularly obvious in the glomerular basement membrane (GBM), which acts as an ultrafiltration unit, located between the capillary and urinary space within the renal glomerulus. Its function is not only as an ultrafilter to produce a filtrate and supporting tissue against the high blood pressure, but it also has nephritogenicity. Nephritogenicity means the ability of an antigen originally from GBM in

Correspondence: Syarifuddin Rauf, M.D., Department of Child Health, Medical School, Hasanuddin University/ Wahidin Sudirohusodo Hospital, Makassar. causing glomerulonephritis, either in experimental animal or in human being.

\section{Glomerular basement membrane structure}

The GBM consists of a rather thick, electron dense central layer (lamina densa, diameter 50 to $100 \mathrm{~nm}$ ) that is bordered on each side by an electro-lucent lamina rara (diameter $20-50 \mathrm{~nm}$ ). Studies on the origin of GBM during embryogenesis show that it is synthesized by both endothelial cells sitting in the capillary and epithelial-like podocytes, which are anchored to the urinary site (Figure 1A).

The main components of GBM are type IV collagen and other matrices, such as laminin, fibronectin, nidogen and heparan sulfate proteoglycan. These components exist as a supra molecular structure (Figure 1B) and serve as a scaffold for the binding and alignment of those extracellular matrices. 
The suprastructure of type IV collagen comprises protomers (building block units) that are linked to one another through end to-end interaction. The protomers are composed of three $\alpha$ chains and is characterized by three structures i.e. $7 \mathrm{~S}$ at the amino terminus, triple helical in the middle region, and NC1 (noncollagenous) domain at the carboxyl terminus (Figure 1C). Protomers are associated in head-to-head (NC1 to NC1) fashion to form dimmers, and in tail-totail (7S to 7S) fashion to form tetramers (Figure 1B). The classical protomer is composed of two of $\alpha 1$ chains and one of $\alpha 2$ chain, where the chains comprise 1609 and 1707 amino acids residues, respectively. ${ }^{2,3}$

Wieslander (1984) was the first who found that the $\alpha 3$ chain of type IV collagen as an auto antigen in Goodpasture syndrome (Figure $1 \mathrm{C}$ and D). ${ }^{2}$ The Goodpasture epitope, the combining site for the pathogenic autoantibody, is recently localized to the carboxyl terminus of the $\alpha 3$ chain (Figure $1 \mathrm{D}$ and $\mathrm{E}$ ).

\section{Nephritogenic antigens in GBM}

Recent studies on basement membrane have revealed that its main component is type IV collagen. There are six different isoforms, namely $\alpha 1$ (IV) to $\alpha 6$ (IV) chain. The complete amino acids sequences of the human 6 chains have already been deduced, as follows: $\alpha 1$ by Brazel et al., ${ }^{3} \alpha 2$ by Brazel et al., ${ }^{4} \alpha 3$ by Mariyama et al., ${ }^{5} \alpha 4$ by Leinonen et al., ${ }^{6} \alpha 5$ by Zhou et al., ${ }^{7}$ and $\alpha 6$ by Zhou et al. ${ }^{8}$.

A globular domain (NC1 domain) at the carboxyl terminus of the type IV collagen $\alpha 3$ chain $\alpha 3$ (IV) NC1, is thought to be an antigen responsible for anti-GBM nephritis. This is based on the fact that autoantibody to $\alpha 3$ (IV) NC1 can be detected in sera of patients with anti-GBM nephritis by Western blotting and by enzyme immunoassay using recombinant $\alpha 3$ (IV) NC1 protein. ${ }^{9-12}$ In addition, $\alpha 4$ (IV) NC1 is also thought to be an antigen responsible for antiGBM nephritis, since experimental anti-GBM nephritis can be induced in rats by injection of synthetic peptide that consisted of parts of the sequences of human $\alpha 3$ (IV) $\mathrm{NC1}$ or $\alpha 4$ (IV) NC1. ${ }^{13}$

Rauf et al. ${ }^{14}$ described the nephritogenicity of NC1 fractions from bovine kidney, lung, and placenta by using monoclonal antibodies. They found that nephritogenicity was apparently a property of $\alpha 3$. $\alpha 5$ (IV) NC1. This finding was supported by Sado, ${ }^{15}$

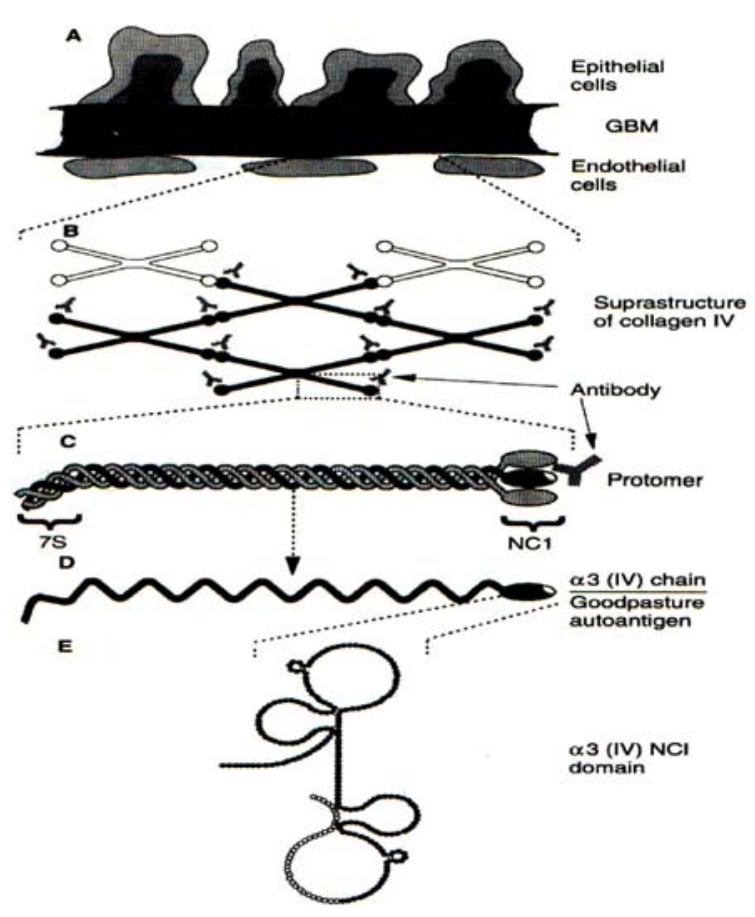

Figure 1. Schematic illustration of the molecule structure of type IV collagen and the Goodpasture autoantigen of renal glomerular basement membrane. ${ }^{2}$

(A) The glomerular basement membrane (GBM) is positioned between epithelial and endothelial

(B) Type IV collagen the mayor constituent of GBM exist as supramolecular network. The dark area denotes collagen triple helical molecules containg the $\alpha 3$ (IV) chain, the Goodpasture autoantigen. The $\alpha 3$ protomers are presumed to form $7 \mathrm{~S}$ domain, analogous to $\alpha 1$ and $\alpha 2$ protomers. The light area denotes the triple helical molecule that do not contain the $\alpha 3(\mathrm{IV})$ chain (Goodpasture antigen). The globular domain of collagen IV is shown as a circle. Antibody localization is shown by an arrow.

(C) The collagen IV molecule at the protomer level with three ? chains, in a triple helical conformotion with carboxyl terminal globular domains. The $\alpha 3$ (IV) chain is shown in dark (evidence suggests presence of $\alpha 3$ homodimers with its globular domain NC1 domain) shown binding the autoantibody at its hypothetical binding site shown in white. $7 \mathrm{~S}$ domain is shown at the $\mathrm{N}$-terminal side.

(D) shows the $\alpha 3$ (IV) NC1 chain, the Goodpasture antigen in its entirety and (E) represents the detailed molecule structure of the NC1 domain with the intra-chain disulfide pairings and the primary interactions site for the autoantibodies (white area). Each dot represents an amino acid residue.

who found that $\alpha 3-\alpha 5$ (IV) NC1 purified from human renal basement membrane could induce antiglomerular basement membrane antibody glomerulonephritis in rats. On the contrary, $\alpha 1$ and $\alpha 2$ (IV) NC1 were not nephritogenic, because NC1 fraction from placental basement membrane which contained of a large amount of $\alpha 1-2$ (IV) NC1, either from bovine, ${ }^{14}$ or human, ${ }^{15}$ (Figure 2 ) could not cause anti- 
GBM nephritis (Figure 3). Also, $\alpha 6$ (IV) NC1 does not seem to be responsible for the induction of the anti-GBM nephritis, because the $\alpha 6$ (IV) chain is absent in the GBM, either in human ${ }^{16}$ or in bovine ${ }^{14}$. Therefore, out of the six $\alpha$ chains only three chains, namely $\alpha 3$ (IV), $\alpha 4$ (IV), and $\alpha 5$ (IV), are nephritogenic antigens.

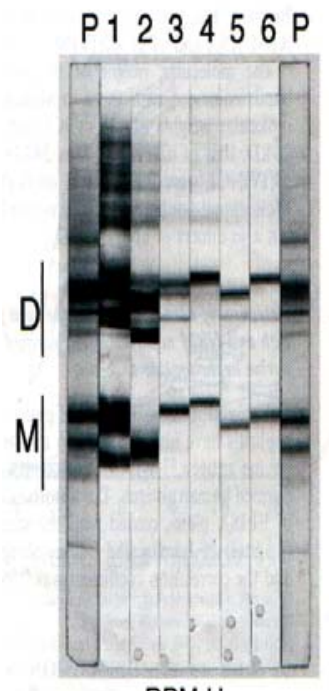

RBM-U

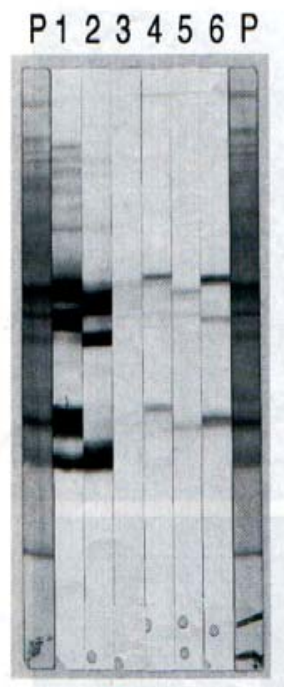

PBM-U
Figure 2. Western blots of NC1 fractions from human renal (RBM$U)$ and placental basement membrane (PBM-U). Monoclonal antibodies: $\mathrm{H} 11$ for $\alpha 1(\mathrm{IV}), \mathrm{H} 22$ for $\alpha 2$ (IV), H33 for $\alpha 3(\mathrm{IV}), \mathrm{H} 43$ for $\alpha 4$ (IV), H52 for $\alpha 5$ (IV), and H63 for $\alpha 6$ (IV). D, Dimer, M, Monomer, P, protein staining, 1-6 immunostaining with chain-spesific monoclonal antibodies. The figure shows that RBM-U contained $\alpha 1-? 6(\mathrm{IV}) \mathrm{NCl}$ and PBM-U have a large amount of $\alpha 1-\alpha 2$ (IV)NC1and a very small amount of $\alpha 3-\alpha 6(\mathrm{IV}) \mathrm{NCl} .{ }^{15}$

\section{Chromosomal location of collagen IV genes}

Genetic studies show that all of the six $\alpha$ chains are encoded by genes located in 2, 13, and X chromosomes. Since the first two human collagen IV genes found, COL 4 A1 and COL 4 A2 were assigned to the same chromosomal locus, namely 13q34. It was hypothesized that additional genes belong to the same subclass are also located in the same region, like in other multi genes families of globin and histone genes, but the other four genes turned out to be on different chromosomes. COL 4 A3 and COL 4 A4 were located on 2 q 35 . q 37 while COL 4 A5 and COL 4 A6 on Xq 22.1
That means the three paired genes were found to reside at the three different chromosomal regions, as is showed in Figure 4.
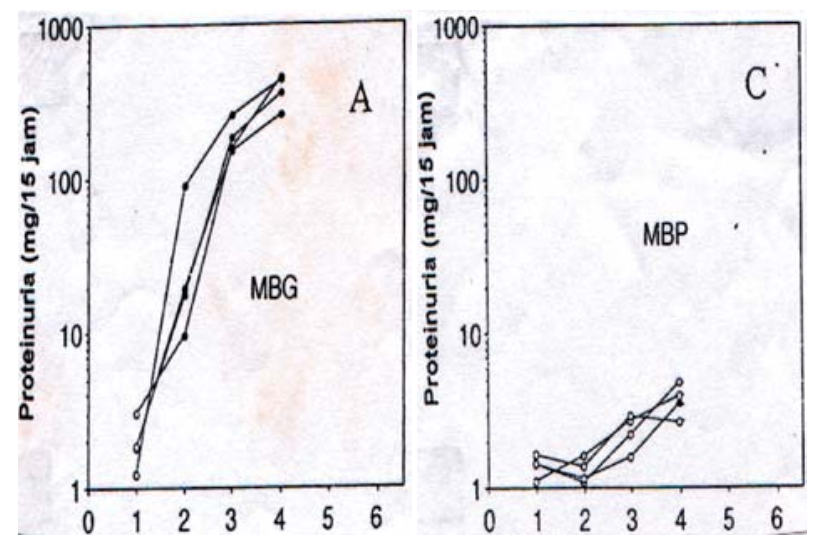

Figure 3. Time course of proteinuria of rats following injections of $300 \mathrm{\alpha g}$ of collagenous-solubilized NC1 fraction from bovine renal (A) and placental (B) basement membrane. The figure shows that NC1 fractions from bovine renal basement membrane caused proteinuria and hematuria, indicating anti-GBM nephritis beginning 2 weeks after injection. On the contrary, bovine placental basement membrane shows no hematuria and very small amount of proteinuria from first week to fourth week after injection. ${ }^{14}$

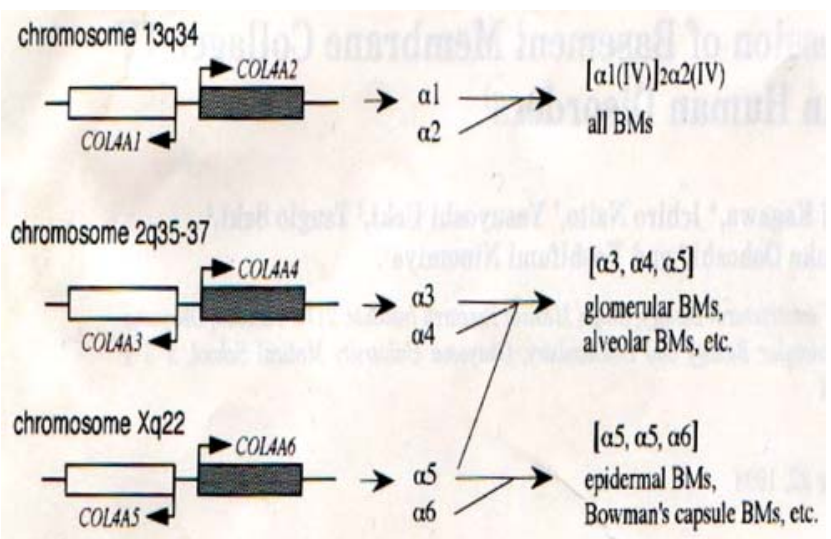

Figure 4. Organisation of collagen IV genes

The six human collagen IV genes are located in pairs in a headto-head manner on the three different chromosomes. These six genes can be classified into two groups. Group A (depicted by white boxes): $\mathrm{COL} 4 \mathrm{~A} 1, \mathrm{COL} 4 \mathrm{~A} 3$, and $\mathrm{COL} 4 \mathrm{~A} 5$ encoding the $\alpha 1, \alpha 3$, and $\alpha 5$ chain, respectively and group $B$ (shaded boxes): COL 4 A 2, COL 4 A 4, COL 4 A 6 encoding the $\alpha 2$, $\alpha 4$, and $\alpha 6$ chains, respectively. These are based on the gene structure,amino acid sequence homology, and the domain structure of the translations products. Three molecules containing of $\alpha 1 / \alpha 2$ chains (located in all basement membranes), $\alpha 3 / \alpha 4 / \alpha 5$ chains (located in glomerular and alveolar basement membranes, etc) and $\alpha 5 / \alpha 6$ chains (located in epidermal, Bowman's capsule basement membranes, etc) are predicted to be present in different basement membranes. ${ }^{1}$ 


\section{The nephritogenicity of GBM in various renal diseases}

\section{Experimental animal}

The nephritogenicity of GBM was first reported in 1962 by Steblay, ${ }^{17}$ who injected multiple doses of insoluble GBM emulsified with adjuvant to sheep, which caused experimental anti-GBM nephritis. Since then, many attempts have been done with success in isolating nephritogenic antigen, either in experimental animal or in human being., ${ }^{9,18}$

There are 2 types of experimental anti GBM nephritis. The active type is revealed by a single injection of a soluble emulsion of nephritogenic antigen in rats ${ }^{19,20}$ while the passive type is yielded by the injection of either homologous polyclonal or monoclonal antibodies to GBM of type IV collagen of GBM. ${ }^{21,22}$

\section{Goodpasture syndrome (GPS)}

Goodpasture syndrome is characterized by a rapidly progressive glomerulonephritis, anti-GBM antibody formation, and pulmonary hemorrhage. This disease is a lethal form of autoimmune disease, because of renal failure or pulmonary hemorrhage. Wieslander for the first time reported that localization of the Goodpasture's antigen is in the noncollagenous region of type IV collagen in GBM. ${ }^{10}$ Goodpasture's antigen is defined as the antigen that react specifically with antibody in the sera of patients with Goodpasture's syndrome. It was then reported that the Goodpasture's antigen is the $\alpha 3$ (IV) NC1. ${ }^{3}$ (Figure 1) Another work analyzes antigen fractions prepared from bovine and human renal basement membranes shows that soluble fractions containing NC1 domains of the $\alpha 3,4$ and 5 are strongly nephritogenic, whereas soluble fraction containing the NC1 domains of the $\alpha 1$ and 2 chains show no or poor nephritogenicity. ${ }^{15,16}$ This suggests that besides $\alpha 3$ chain, $\alpha 4$ and 5 are also involved in the pathogenesis of experimental Goodpasture syndrome.

\section{Alport syndrome}

Alport syndrome is an inherited disease characterized by sensorineural deafness and hematuria with relentless progression to end-stage renal disease. The renal lesion is characterized by ultrastructural abnormalities namely thinning, thickening, diffuse splitting and multi lamination of the lamina densa in the GBM. Extensive research over the past decades have extended our knowledge on the clinical, ultrastructural and genetic features of Alport syndrome, and have elucidated the molecular genetic basis of the disease. Alport syndrome is now understood as a disease of specific type IV collagen chain, caused by gene mutation of the $\alpha 3$ (IV), $\alpha 4$ (IV), and $\alpha 5$ (IV) of type IV collagen.

The genes of the $\alpha 3$ (IV) and $\alpha 4$ (IV) chains are on chromosome 2 in a head-to-head fashion, whereas the gene for the $\alpha 5$ (IV) chain resides on chromosome X.

The distribution pattern of the six $\alpha$ chains suggests that there are three combinations of $\alpha$ chains, ${ }^{1}$ namely combination of two of $\alpha 1$ and one of $\alpha 2$ chains $(\alpha 1 / \alpha 1 / \alpha 2)$, combination of $\alpha 3, \alpha 4$, and $\alpha 5$ chains $(\alpha 3 / \alpha 4 / \alpha 5)$, and combination of two of $\alpha 5$ and one of $\alpha 6(\alpha 5 / \alpha 5 / \alpha 6) .{ }^{23}$ In the kidney of male patients with typical X-linked Alport's syndrome, the $\alpha 3$ to $\alpha 6$ chains are missing, suggesting that molecules having the $\alpha 3 / \alpha 4 / \alpha 5$ and $(\alpha 5 / \alpha 5 / \alpha 6)$ are absent. In the kidney of female patients with X-linked Alport syndrome, a discontinuous pattern (mosaic pattern) is observed. This is due to inactivation of chromosome X. One of the two chromosomes X is inactivated randomly in a mosaic pattern in the whole body; so if the normal X chromosome is activated, the $\alpha 3 /$ $\alpha 4 / \alpha 5$ and $(\alpha 5 / \alpha 5 / \alpha 6)$ are present, and if the abnormal X chromosome is activated, no such combinations of molecules is present. On the contrary, when gene mutations are present in the genes encoding the $\alpha 3$ or $\alpha 4$ chain, the mode of inheritance is an autosomal recessive form. The consequence of this mutation is no $\alpha 3 / \alpha 4 / \alpha 5$ present in the GBM. ${ }^{24}$

The absence or the decrease of the content of $\alpha 3 / \alpha 4 / \alpha 5$ molecules in the GBM will lead the disease, to both, X-linked and autosomal recessive forms. This fact is now used for diagnosis of Alport's syndrome by immunohistochemical staining of cryostat section and paraffin-embedded section with monoclonal antibodies. ${ }^{25-27}$

From the clinical point of view, based on the presence of molecules $\alpha 3 / \alpha \quad 4 / \alpha \quad 5$ which are nephritogenic, a small number of patients (about 5 $\%$ with Alport syndrome develops Goodpasture syndrome after renal transplantation. ${ }^{28}$ This is because 
the Goodpasture antigen ( $\alpha 3$ chain) is absent in the kidney of patients with Alport syndrome, so consequently the $\alpha 3$ chain in the new kidney is recognized as a foreign antigen and leads to the antibody anti-GBM formation.

\section{References}

1. Sado Y, Kagawa M, Naito I, Ueki Y, Seki T, Momota $\mathrm{R}$, et al. Organization and expression of basement membrane collagen IV genes and their roles in human disorders. J Biochem 1998;123:767-76.

2. Hudson BG, Wieslander J, Wisdom BJ, Noelken ME. Biology of disease: Goodpasture syndrome: molecular architecture and function of basement membrane antigen. Lab Invest 1989;61:256-69.

3. Brazel D, Obermaumer I, Dieringer H, Babel W, Glanville RW, Deutzmann R, et al. Complication of the amino acid sequence of ? 1 chain of human basement membrane collagen (type IV) reveals 21 nontripleinterruptions located with in the collagenous domain. Eur J Biochem 1987;168:529-36.

4. Brazel D, Pollner R, Obermaumer I, Kuhn K. Human basement membrane collagen (type IV). The amino acid sequence of the ? 2 (IV) and its comparison with the ? 1 (IV) chain reveals deletions in the ? 1 (IV) chain. Eur J Biochem 1988;172:35-42.

5. Mariyama M, Leinonen A, Mochizuki T, Tryggvason K, Reeders ST. Complete primary structure of the human ? 3 (IV) collagen chain : coexpression of the ? 3 (IV) and? 4 (IV) collagen chains in human tissues. J Biol Chem 1994:269:23013-7.

6. Leinonen A, Mariyama M, Mochizuki T, Tryggvason $\mathrm{K}$, Reeders ST. Complete primary structure of the human type IV collagen ? 4 (IV) chain. J Biol Chem 1994;269:26172-7.

7. Zhou J, Hertz JM, Leinonen A, Tryggvason K. Complete animo acid sequence of the human ? 5 (IV) collagen chain and identification of single-base mutation in exon 23 converting glycine 521 in the collagenous domain to cysteine in Alport syndrome patient. J Biol Chem 1992;269:12475-81.

8. Zhou J, Ding M, Zhao Z, Reeders ST. Complete primary structure of the sixth chain of human basement membrane collagen? 6 (IV). J Biol Chem 1994;269:13193-9.

9. Wieslander J, Barr JF, Butkowsky RJ, Eair Sulingards SJ, Bygren P, Heinegard D, et al. Goodpasture antigen of the glomerular basement membrane: localization to non collagenous region of the type IV collagen. Proc. Natl Acad Sci USA 1984;81:3838-42.

10. Wieslander J, Langeveld J, Butkouski RJ, Jodlowski M, Noelken M, Hudson BG. Physical and immunohis- tochemical studies of the globular domain of the type IV collagen. J Biol Chem 1985;260:8564-70.

11. Butkowsky RJ, Wieslander J, Wisdom BJ, Barr JF, Noelken ME, Hudson BG. Properties of the globular domain and its relationship to the Goodpasture antigen. J Biol Chem 1985;260:3739-47

12. Butkowsky RJ, Langeveld JPM, Wieslander J, Hamilton J, Hudson BG. Localization of the Goodpasture epitope to a novel chain of basement membrane collagen. J Biol Chem 1987;262:7874-7.

13. Butkowsky RJ, Guo-Qiu Shen, Wieslander J, Michael AF, Fish AJ. Characterization of type IV collagen NC! monomers and Goodpasture antigen in human renal basement membrane. J Lab Clin Med 1990;115:365-73.

14. Rauf S, Kagawa M, Kishiro Y, Inonue S, Naito I, Oohashi T, et al. Nephritogenicity and ? - chain composition of NC1 fraction of type IV collagen from bovine renal basement membrane. Virchows Arch 1996;428:281-8.

15. Sado Y, Kagawa M, Kishiro Y, Naito I, John K, Ninomiya Y. Purification and characterization of human nephrotigenic antigen that induces anti-GBM nephritis in rats. J Pathol 1997;182:225-32.

16. Ninomiya Y, Kagawa M, Iyama K, Naito I, Kishiro Y, Seyer JM, et al. Differential expression of two basement membrane collagen genes, Col 4 ? 6 and Col 4 ? 5, demonstrated by immunofluorescence staining using peptide-spesific monoclonal antibodies. J Cell Biol 1995;130:1219-29.

17. Steblay RW. Glomerulonephritis induced in sheep by injection of heterologous glomerular besement membrane and Freund's complete adjuvant. J Exp med 1962;116:25369.

18. Sado Y, Okogaki T, Takamiya H, Seno S. Experimental autoimmune glomerulonephritis with pulmonary haemorrhage in rats. The dose-effect relationship of the nephritogenic antigen from bovine glomerular basement membrane. J Clin Lab Immunol 1984;15:199-204.

19. Shibata S, Nagasaawa T, Mikayawa Y, Naruse T. Nephritogenic glycoprotein : proliferative glomerulonephritis induced in rats by single injection of the soluble glycoprotein isolated from homologous glomerular basement membrane. J Immunol 1971;106:1284-94.

20. Sado Y, Naito I. Experimental autoimmune glomerulonephritis in rats by soluble isologous or homologous antigen from glomerular and tubular basement membranes. $\mathrm{Br} J$ Path 1987;68:695-704.

21. Sado Y, Naito I, Okigaki T. Transfer of anti-glomerular basement membrane antibody -induced glomerulonephritis in inbred rats with isologous antibodies from the urine of nephritic rats. J Pathol 1989;158:325-32.

22. Sado Y, Kagawa M, Rauf S, Naito I, Moritoh C, Okigaki T. Isologous monoclonal antibodies can induce anti-GBM glomerulonephritis in rats. J Pathol 1992;168:221-7. 
23. Sado Y, Naito I, Ninomiya Y. Expression of collagen IV genes and Goodpasture Antigens. In Y. Ninomiya, ed. Extracellular matrix-cellular interaction. Japan ScSOC Press Tokyo/S Kargo Basel; 1998. p. 235-60.

24. Gubler MC, Knebelmam B, Beziau A, Brayer M, Pirson Y, Haddoum F, et al. Autosomal recessive Alport syndrome: immunohistochemical study of type IV collagen chain distribution. Kidney Int 1995;47:1142-7.

25. Naito I, Kawai S, Nomura S, Sado Y, Osawa G. The Japanese Alport Network. Relationship between Col 4A5 gene mutation and distribution of type IV collagen in male X-linked Alport syndrome. Kidney Int 1996;50:304-11.
26. Kagawa M, Kishiro Y, Naito I, Nemoto T, Nakamishi $\mathrm{H}$, Ninomiya $\mathrm{Y}$, et al. Epitope defined monoclonal antibodies against type IV colagen for diagnosis of Alport's syndrome. Nephrol Dial Transport 1997;12:1238-41.

27. Rauf S. Penggunaan antibodi monoklonal untuk menunjang diagnosis sindrom Alport J Med Nus 1999;20:34-40.

28. Scolari F, Valzorio B, Fasciolo F, Carli O, Vizzarrdi V, Gaggia P, et al. Kidney transplantion in Alport's syndrome. In: Sessa A, Conte F, Meroni M, Battini G, eds. Hereditary kidney diseases. Contrib. Nephrol Basel, Karger; 1997. p. 140-2. 